\title{
Design de informação em interfaces digitais: origens, definições e fundamentos
}

\author{
Information design: origins, definitions and foundations
}

Fernanda S. Quintão, Ricardo Triska

design de informação, usuário, conteúdo
Information design, user, content
Nos dias atuais, o design envolve a produção não só de objetos materiais, mas também de interfaces gráfico-digitais, utilizadas para a interação no ciberespaço. Existem pontos de contato entre o design de informação e o design de interfaces, uma vez que ambas as disciplinas lidam com informações e signos. São identificados dois marcos para a origem do design de informação, ambos oriundos da década de 1930: o mapa das linhas de metrô de Londres, de autoria de Harry C. Beck, e o trabalho desenvolvido por Otto Neurath, que introduziu o método Isotype. Observase que diferentes definições para a disciplina ou campo de estudo destacam a importância do usuário no processo do design de informação. São apresentados seus fundamentos, a partir dos estudos de Bertin, Mijksenaar, Tufte e Redig. Percebe-se a necessidade de se atentar às possíveis estratégias para se reforçar, diferenciar e suportar conteúdos a serem apresentados aos usuários, seja em suporte físico ou digital.

Nowadays, design involves the production of not just material objects, but also graphicdigital interfaces, used for interaction in cyberspace. There are touch points between information design and interface design, since both disciplines deal with information and signs. Two milestones are identified as origin of information design, both from the 1930s: the map of London Underground lines, designed by Harry C. Beck, and the work developed by Otto Neurath, who introduced the Isotype method. Different definitions for this discipline or study field highlight the importance of the user in the design information process. Its foundations are presented, based on researches by Bertin, Mijksenaar, Tufte and Redig. We realize the need to be alert to possible strategies to enhance, differentiate and support contents to be presented to users, whether in physical or digital supports.

\section{0 design como interface}

Desde a sua origem, no final do século XVIII, o conceito de design sofreu inúmeras transformações. No entanto, esse processo se intensificou ainda mais a partir do século XX, devido aos avanços tecnológicos que possibilitaram a configuração de diferentes tipos de produtos. Nos dias atuais, o design envolve a produção não só de 
objetos materiais, mas também de interfaces gráfico-digitais, com as quais o usuário interage no ciberespaço.

O design se orienta à interação entre usuário e produto, o que faz com que o domínio do design seja o domínio da interface, um domínio em que é estruturada a interação entre usuários e artefatos (BONSIEPE, 1997a), tanto artefatos físicos e instrumentais na forma de produtos, quanto artefatos semióticos na forma de signos (BONSIEPE, 1997b).

Em seu diagrama ontológico do design (Figura 1), Bonsiepe (1997a) apresenta o usuário (corpo), a ação (objetivo) e a ferramenta (ou informação) como campos heterogêneos que se unem a partir da interface: "design industrial é essencialmente design de interfaces" (BONSIEPE, 1997a, p. 31).

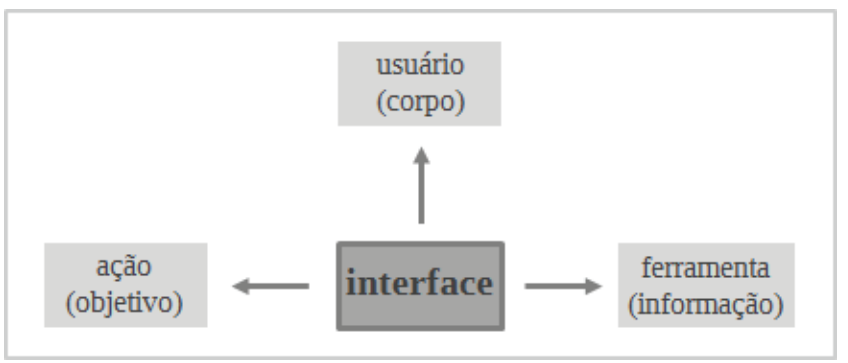

Figura 1 Diagrama ontológico do design.

(Fonte: Elaborado pelos autores, a partir de Bonsiepe (1997a))

Bonsiepe abordou a produção de interfaces gráfico-digitais como área de atuação do design, por incluir aspectos relacionados a elementos gráficos e à cognição do usuário, indo além da engenharia de usabilidade. Frascara (2004) comprova o ponto de vista de Bonsiepe, ao afirmar que a busca por designers é cada vez maior principalmente devido ao rápido desenvolvimento das tecnologias de informação e à necessidade de se dar atenção aos fatores humanos, que estão além das habilidades de programadores.

A interface, no ciberespaço, se torna tão importante porque nele tudo é interface, tudo é design: a interface abrange tudo (BONSIEPE, 1997a). Cardoso (2012, p. 207) afirma que "a Internet jamais teria alcançado sua repercussão atual se não fosse pela elaboração das interfaces gráficas que dão sustentação à world wide web". As interfaces gráfico-digitais convidam o usuário a interagir no ciberespaço, permitindo a navegação e o acesso a dados inimagináveis em um passado recente.

Para Johnson (2001), a interface se apresenta como o espaço entre o meio e a mensagem, como um tradutor, que media homem e mundo digitalizado. Cardoso (2012) reforça o caráter de mediação da interface. Para ele, a interface é o dispositivo que opera a ligação entre dois pontos que fazem parte de uma rede composta por muitos sistemas. Se essa ligação não permite o fluxo desejado, a rede pode ser desfeita ou prejudicada (CARDOSO, 2012). Assim, é importante que as interfaces sejam projetadas, atividade que cabe ao designer: "do ponto 
de vista de sua difusão social, a rede é um fenômeno tanto de design quanto de informática" (CARDOSO, 2012, p. 207).

De acordo com Lemos (1997), a interface digital atua como um mediador cognitivo. A mediação é criada a partir de uma ação que envolve agentes múltiplos e é iniciada pelo usuário através da manipulação direta da informação. Para Bonsiepe (2011), há pontos de contato entre o design de informação e o design de interfaces, uma vez que ambas as disciplinas lidam com informações e signos.

De acordo com Horn (2000), a mesma atividade recebe nomes diferentes, dependendo do local em que se desenvolve: em jornais e revistas, é chamada de gráficos de informação; em empresas, de gráficos de apresentação ou de negócios; na área científica, é conhecida como visualização científica; na computação, é design de interação; na arquitetura é sinalização ou wayfinding, e, finalmente, no design gráfico é chamada apenas de design.

Vale ressaltar que, no presente artigo, consideram-se sinônimas as palavras "receptor", "destinatário" e "usuário", uma vez que, no contexto do design de informação, dizem respeito àquele a quem uma informação ou conteúdo se dirige, seja em meio analógico ou digital.

\section{0 design de informação}

Shedroff (2000) afirma que os princípios do design de informação têm origem no design gráfico e editorial. Para o autor, a disciplina tem como objetivo organizar e apresentar dados, transformando-os em informação com sentido e valor. Seu objetivo não é substituir o design gráfico e outras disciplinas visuais, mas oferecer a estrutura necessária para que elas expressem suas capacidades.

O mapa das linhas de metrô de Londres, projetado pelo desenhista Harry C. Beck e concluído em 1933, foi fundamental para o desenvolvimento do design de informação, segundo Royo (2008). O autor destaca que Beck "propôs o design que substituía a fidelidade geográfica por uma interpretação diagramática” (ROYO, 2008, p. 51), utilizando diferentes escalas para representar as áreas centrais, que tinham maior complexidade de linhas em relação às áreas periféricas, além de identificar as linhas com cores que se diferenciavam visualmente umas das outras.

A forma de organizar informações desenvolvida por Beck foi tão importante que os mapas e infográficos disseminados em meios de comunicação da atualidade "são herdeiros diretos daquela representação" (ROYO, 2008, p.52).

Também o trabalho desenvolvido por Otto Neurath, filósofo e economista austríaco que, na década de 1930, enquanto era diretor do Museu da Sociedade e Economia de Viena, introduziu o método Isotype, continua sendo fonte de inspiração para designers gráficos e contribuiu para o desenvolvimento de pictogramas e, 
indiretamente, dos infográficos popularizados em jornais e revistas (MIJKSENAAR, 1997).

O Isotype, acrônimo para International System of Typographic Picture Education - ou Sistema Internacional de Educação pela Imagem Tipográfica - era um método para montagem, configuração e disseminação da informação estatística utilizando meios pictóricos que, na época de sua criação, ajudou a explicar e ilustrar questões sociais e econômicas ao público leigo (WALKER, 2012, p. 345). Era composto por imagens gráfico-pictóricas que podiam ser reproduzidas e utilizadas em exposições do Museu da Sociedade e Economia de Viena. Neurath viu o potencial da aplicação de imagens simplificadas para informar adultos menos instruídos e crianças em idade escolar, mas também para comunicações internacionais (BURKE, 2009).

Segundo Mijksenaar (1997), no centro do método Isotype estava um dicionário visual, que continha certa de dois mil símbolos, e uma gramática visual, que tornava possível transmitir informações de tal maneira que elas poderiam ser apreendidas quase imediatamente. De acordo com Burke (2009), os pictogramas do Isotype deveriam ser signos que falassem por si mesmos, sendo autoexplicativos, e que pudessem contornar a linguagem verbal, não a substituindo, mas servindo como apoio.

A principal contribuição do Isotype para a comunicação visual, segundo Meggs e Purvis (1998), foi o conjunto de convenções desenvolvido para formalizar o uso da linguagem pictórica, incluindo uma sintaxe e o design de pictogramas simplificados. Os autores também afirmam que o impacto do método no design após a $2^{2}$. Guerra Mundial foi, além da pesquisa relacionada ao desenvolvimento de sistemas universais de linguagem visual, o uso extensivo de pictogramas em sinalização e sistemas de informação.

\subsection{Definições}

O International Institute for Information Design - IIID, fundado na Áustria em 1986, caracteriza o design de informação como “a definição, planejamento e modelagem dos conteúdos de uma mensagem e do ambiente em que ela é apresentada, com a intenção de satisfazer às necessidades de informação dos destinatários.” (IIID, 2007). Ao incluir a definição dos conteúdos como característica do design de informação, o IIID sugere que o profissional da área deva participar ativamente do processo de elaboração do material a ser desenvolvido desde suas etapas iniciais. Também se observa que o usuário, ou seja, aquele a quem a informação se destina, exerce um papel importante para o processo do design de informação.

No Brasil, a Sociedade Brasileira de Design da Informação SBDI foi fundada em 2002 e define o design de informação como:

uma área do design gráfico que objetiva equacionar os aspectos sintáticos, semânticos e pragmáticos que envolvem os sistemas de informação 
através da contextualização, planejamento, produção e interface gráfica da informação junto ao seu público alvo. Seu princípio básico é o de otimizar o processo de aquisição da informação efetivado nos sistemas de comunicação analógicos e digitais.” (SBDI, 2006)

Assim, para a SBDI, o design de informação é subordinado ao design gráfico, contrariando a fala de Horn (2000) citada anteriormente, para quem o design de informação é chamado apenas design quando considerado no âmbito do design gráfico, ou seja, entre o design gráfico e o design de informação não haveria uma hierarquia definida. Por outro lado, a definição apresentada pela SBDI parece confirmar a presença de pontos de contato entre o design de informação e o design de interfaces, defendida por Bonsiepe (2011), uma vez que afirma que o design de informação atua em sistemas de comunicação presentes tanto em meios analógicos quanto digitais.

Bonsiepe (1999) caracteriza o design de informação com um domínio em que os conteúdos são visualizados por meio de seleção, ordenamento, hierarquização, conexões e distinções visuais que permitem uma ação eficaz, sem que seja definido o meio em que tais conteúdos estão disponibilizados. O autor ainda afirma que a maneira como dados e informações são apresentados tem um papel importante, e que o design pode facilitar a recepção e interpretação, permitindo, assim, uma ação mais eficiente (BONSIEPE, 2011, p. 84).

No cenário atual da sociedade contemporânea de informação, o design de informação, para Frascara (IIID, 2011), não é apenas uma profissão técnica, mas uma necessidade social, pois possibilita que o grande volume de informações com que lidamos atualmente seja claro, criando, assim, homogeneidade de acesso ao que pode ser oferecido. Segundo o autor, o objetivo do design de informação é assegurar a efetividade da comunicação a partir da facilitação de processos de percepção, leitura, compreensão, memorização e uso da informação apresentada (FRASCARA, 2011). A eficiência na apreensão de informações também é destacada em Jacobson (2000), para quem o design de informação vai aprimorar a capacidade de nossa sociedade em coletar, processar e disseminar informação e de produzir entendimento.

Projetar informações, para Bonsiepe (1999), significa ordenar uma massa de partículas informáticas e ajudar os usuários a se mover no espaço informático, reduzindo sua carga cognitiva. Malamed (2009) reforça a colocação de Bonsiepe, ao afirmar que devemos apreciar o fato de que elementos visuais reduzem o tempo que um usuário leva para entender e responder a uma informação.

No entanto, para Bonsiepe (1999), o design de informação é mais que uma tradução para a linguagem visual, uma vez que o trabalho do designer de informação se inicia com a estruturação dos conjuntos de dados. Dessa maneira, mais do que um simples tradutor, o designer atua como um coautor. Nesse sentido, Bonsiepe (1999) vai ao encontro da caracterização de design de informação apresentada 
pelo IIID (2007), segundo o qual a definição de conteúdos é uma das características desse campo do design.

Bonsiepe (1999) destaca a amplitude do design de informação, ao elencar algumas de suas possíveis áreas de atuação: projeto de interfaces, imagens médicas, diagramas e manuais, mapas e planos de orientação digitais, design de informação para crianças, design de informação para televisão, gerenciamento de informações, entre outros. Assim, percebe-se que, no contexto atual da presença crescente da quantidade de informações com que temos contato em nosso cotidiano, o design de informação pode exercer um papel social fundamental, no sentido de fazer com que tais informações sejam disponibilizadas de maneira clara e objetiva para aqueles que, seja por necessidade ou desejo, têm contato com elas, conforme o exposto por Frascara (2011).

Para Jacobson (2000), existe uma área de atuação que pode ser identificada como design de informação, e seu propósito são a organização e o uso sistemático de canais de comunicação para aumentar o entendimento daqueles que participam de uma conversa ou discurso específico.

Horn (2000) reforça a relação do design de informação com os usuários, ao afirmar que ele pode ser definido como a arte e a ciência de tratar a informação, de modo que ela possa ser utilizada, com eficiência e eficácia, pelas pessoas. Observa-se que a definição elaborada por Horn (2000) fortalece a relação entre design de informação e eficiência, presente nas definições apresentadas por SBDI (2006), Bonsiepe (2011), Frascara (2011) e Jacobson (2000).

Os objetivos do design de informação, de acordo com Horn (2000) são: (1) o desenvolvimento de documentos que sejam compreensíveis, recuperáveis com rapidez e precisão, e fáceis de se traduzir para uma ação efetiva; (2) o projeto de interações com equipamentos que sejam fáceis, naturais e agradáveis, o que pode vir a solucionar problemas no design de interfaces humano-computador; e (3) a possibilidade de permitir que as pessoas consigam se orientar em um espaço tridimensional com facilidade e conforto, sendo esse espaço principalmente o espaço urbano, mas também o espaço virtual. Percebe-se, portanto, que o autor não diferencia o design de informação do design de interfaces ou interações, considerando o primeiro como responsável pela disponibilização, de forma compreensível e agradável, de informações a pessoas que, por algum motivo, tenham que lidar com essas informações, estejam elas disponíveis em meios analógicos ou digitais.

Os designers de informação, segundo o International Institute for Information Design (2007), facilitam a transferência de conhecimento ao tornar a informação, fornecida por aqueles que a sabem, acessível e compreensível àqueles que não a sabem, mas desejam saber. Os profissionais fazem isso ao considerar o caráter da informação de ser relacionada à tarefa a ser desempenhada e orientada ao objetivo que se pretende alcançar. 


\subsection{Fundamentos}

Gráficos, diagramas e ilustrações passaram a ser utilizados como ferramentas para o pensamento visual há cerca de duzentos anos, de acordo com Ware (2008). Com o desenvolvimento tecnológico e a consequente possibilidade de utilização da imagem em movimento na web, a visualização de dados se tornou ainda mais complexa.

Frascara (2004) afirma que o design de informação é desenvolvido em duas etapas: a organização da informação e o planejamento de sua apresentação. Para o autor, tais tarefas exigem a habilidade de processar, organizar e apresentar informações de maneira verbal e não verbal, uma vez que a acuidade visual e a compreensão são preocupações centrais do design de informação..

Um bom design de informação, de acordo com Frascara (2011), faz com que a informação seja acessível - disponível de maneira fácil -, apropriada ao conteúdo e ao usuário, atrativa - convidando a ser lida ou compreendida -, confiável, completa, concisa, relevante - de acordo com o objetivo do usuário -, oportuna - estando onde e quando o usuário necessita dela -, compreensível e apreciada por sua utilidade. Para o autor, um bom design de informação convida a ser usado, reduz o cansaço e erros no processamento de informações, acelera o trabalho e faz com que a informação seja atrativa e adequada à situação em que se apresenta.

Já Mijksenaar (1997) apresenta alguns recursos utilizados por designers para dar forma à informação que se deseja expor: enfatizar ou minimizar; comparar ou ordenar; agrupar ou classificar; selecionar ou omitir; optar pelo reconhecimento imediato ou tardio; e apresentá-la de forma divertida e interessante. Para isso, o designer pode fazer uso, de acordo com o autor, de variáveis visuais descritas pelo cartógrafo francês Jacques Bertin na década de 1970.

Bertin foi um pioneiro ao compreender não apenas aspectos técnicos relacionados à apresentação gráfica de informações, mas também os padrões e processos geográficos que ele gostaria de comunicar (FIELD, 2011). Segundo Morita (2011), o legado de Bertin foi o estabelecimento de uma estrutura que permitisse a elaboração de mapas mais claros. No entanto, a importância de sua obra não se restringe ao domínio da cartografia, sendo destacada também por pesquisadores relacionados à visualização de informações (KRAAK, 2011), como o próprio Mijksenaar. Morita (2011) sublinha, ainda, que a teoria de Bertin é mais fácil de ser aplicada atualmente, a partir da utilização de meios digitais.

Para Bertin, a percepção visual é ubíqua, ou seja, quando lemos uma imagem, passamos por três níveis de percepção - a imagem completa, uma parte dela e um elemento - e a alternância entre eles é praticamente automática, não exigindo nenhum tipo de esforço especial (MORITA, 2011). Assim, Bertin concebeu um sistema de signos como uma forma de gráficos operacionais para descobrir a estrutura 
oculta dos fenômenos derivados da articulação de padrões visuais (MORITA, 2011).

A partir de aspectos como posição, forma, tamanho, contraste, saturação, cor e direção, é possível organizar elementos de informação de modo a apresentá-los de maneira adequada ao seu objetivo e ao usuário.

As variáveis visuais podem ser visualizadas na Figura 2, a seguir.

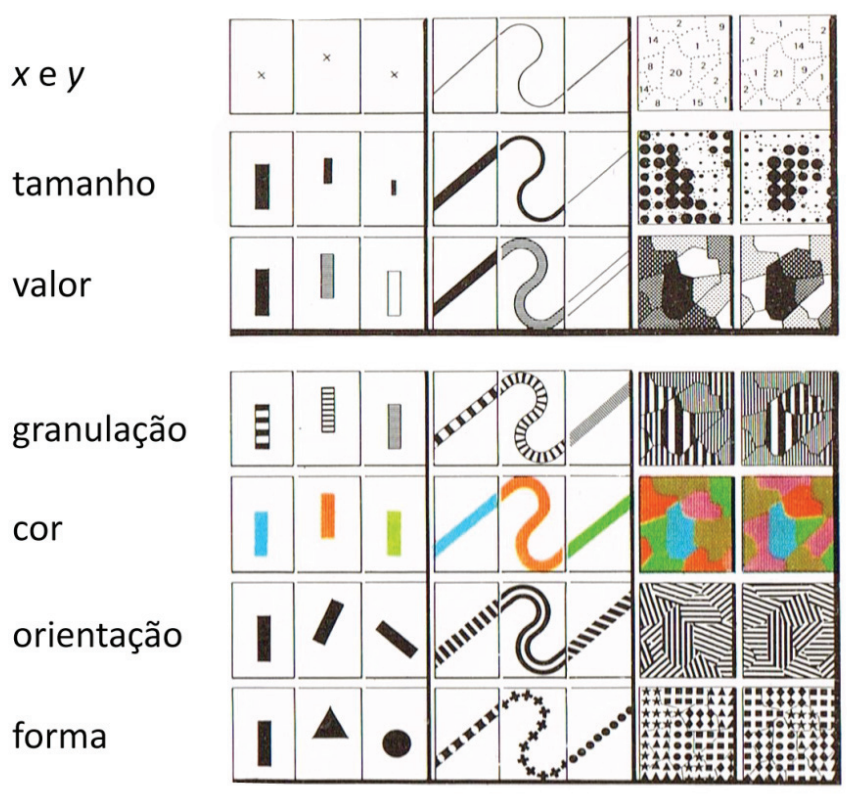

Figura 2 Variáveis visuais

(Fonte: Elaborado pelos autores, a partir de Bertin (1986))

São definidas oito variáveis visuais, de acordo com Bertin (1986): (1) coordenada x e (2) coordenada y, que indicam o posicionamento no espaço bidimensional; (3) tamanho, variável quantitativa, utilizada para informar dados numéricos ou ordem de importância; (4) valor, variável qualitativa, que diz respeito à variação do branco ao preto; (5) forma, utilizada para representar elementos similares e diferentes, e para facilitar a identificação dos elementos, a partir do uso de algumas convenções, como um quadrado com uma cruz para representar uma igreja; (6) orientação, que se refere ao ângulo de posicionamento dos elementos; (7) granulação, utilizada para diferenciar áreas ou linhas a partir de texturas; (8) cor, diz respeito à variação de um matiz (do cinza à cor pura).

Mijksenaar (1997) adaptou as variáveis visuais ao design, apresentando a utilização de elementos gráficos (Quadro 1). 
Quadro 1 Adaptação das variáveis visuais de Bertin para o design (Fonte: Elaborado pelos autores, a partir de Mijksenaar (1997))

\begin{tabular}{|c|c|}
\hline $\begin{array}{l}\text { Diferenciação } \\
\text { classifica de acordo com a } \\
\text { categoria e o tipo }\end{array}$ & $\begin{array}{l}\text { cor } \\
\text { ilustrações } \\
\text { largura de coluna } \\
\text { fonte tipográfica }\end{array}$ \\
\hline $\begin{array}{l}\text { Hierarquia } \\
\text { classifica de acordo com a } \\
\text { importância }\end{array}$ & $\begin{array}{l}\text { posição sequencial (cronologia) } \\
\text { Posição na página (leiaute) } \\
\text { tamanho da fonte } \\
\text { peso da fonte } \\
\text { espaçamento de linhas }\end{array}$ \\
\hline $\begin{array}{l}\text { Apoio } \\
\text { classifica de acordo com a } \\
\text { categoria e o tipo }\end{array}$ & $\begin{array}{l}\text { áreas de cores e sombras } \\
\text { linhas e blocos } \\
\text { símbolos, logos, ilustrações } \\
\text { atributos do texto (itálico, etc.) }\end{array}$ \\
\hline
\end{tabular}

Ao adaptar ao design as variáveis visuais definidas por Bertin (1986), Mijksennar (1997) se apoia em um sistema consolidado e explicita de que maneira diferentes elementos gráficos podem ser utilizados, observando-se os aspectos que se deseja reforçar ao se transmitir informações visualmente. Assim, o autor define duas categorias principais: as de diferenciação, que indicam distinção de tipos, e podem ser expressas a partir do uso de cores e formas, e as hierárquicas, que indicam diferença de importância, a partir da utilização de tamanho e intensidade. Também existem elementos visuais que podem ser aplicados como apoio, como áreas de cor, linhas e blocos, que possuem a função de acentuar e organizar informações (MIJKSENAAR, 1997).

Tufte (2001) apresenta três princípios gerais de excelência gráfica: (1) a apresentação bem planejada de dados interessantes, uma questão de substância, estatística e design; (2) a comunicação de ideias complexas com clareza, precisão e eficiência; e (3) o oferecimento, ao usuário, do maior número de ideias no menor tempo possível, com a menor quantidade de tinta no menor espaço. No entanto, a obra de Tufte diz respeito principalmente ao design de informação de dados quantitativos e, portanto, os princípios por ele apresentados nem sempre são aplicáveis quando se trata de informações qualitativas.

Tufte (2006) também apresenta os princípios fundamentais do design analítico: (1) comparações; (2) causalidade, mecanismo, estrutura, explanação; (3) análise multivariada; (4) integração de evidências; (5) documentação; e (6) a importância do conteúdo.

O primeiro princípio é apresentado como "Mostre comparações, contrastes, diferenças” (TUFTE, 2006:127). Para o autor, é fundamental apresentar comparações inteligentes e apropriadas, seja ao avaliar mudanças ao longo do tempo ou do espaço, ao procurar grandes bases de dados, ao ajustar e controlar variáveis ou ao projetar experimentos, entre outros exemplos. 
Para o segundo princípio, a ordem é "Mostre causalidade, mecanismos, explicações, estrutura sistemática” (TUFTE, 2006, P. 128). A pesquisa científica, por exemplo, se baseia no modelo de causa e consequência, assim como a análise médica. Muitas vezes procuramos evidências para entender as causas e os mecanismos de funcionamento de algo.

No terceiro princípio, o autor indica: "Mostre dados multivariados, ou seja, mostre mais do que 1 ou 2 variáveis" (TUFTE, 2006, P. 130). Algumas dessas variáveis podem ser o tamanho, a posição, a direção, entre outras.

O quarto princípio de Tufte (2006, p. 131) é: "Integre completamente palavras, números, imagens, diagramas”. O autor apresenta algumas estratégias para que essa integração seja bem realizada, como a utilização adequada de cores e transparências, por exemplo.

No quinto princípio, o autor é mais detalhado: "Descreva minuciosamente as evidências. Forneça um título adequado, indique autores e responsáveis, documente fontes de dados, mostre escalas de medidas, aponte questões relevantes" (TUFTE, 2006, P. 133). A documentação é um item essencial para o controle de qualidade da informação e indica cuidado a se tratar o material.

O sexto e último princípio fundamental do design analítico é claro: "Apresentações analíticas, em última instância, obtêm sucesso ou fracassam dependendo da qualidade, relevância e integridade do seu conteúdo" (TUFTE, 2006, P. 136). Segundo Tufte, isso sugere que a melhor maneira de executar uma boa apresentação é ter um bom conteúdo para apresentar. Sugere, ainda, que um bom design não é capaz de salvar um conteúdo fraco. Assim, a primeira pergunta a se fazer ao iniciar um projeto de apresentação de informações deve ser "quais são as tarefas baseadas no conteúdo que essa apresentação deve ajudar?". Para Tufte (2006), ao responder a essa questão será possível levantar opções para os elementos de conteúdo, organização e tecnologias possíveis.

Redig (2004) aponta a importância social do design de informação, ao afirmar que ele está no eixo do sistema democrático, uma vez que não há democracia sem informação clara e verdadeira. Diferente dos autores citados anteriormente, Redig (2004) inclui o destinatário da mensagem, a forma da mensagem e o tempo de transmissão da mensagem como aspectos característicos do design de informação.

Em relação ao destinatário da mensagem, o autor destaca a necessidade de se levar em conta o receptor da informação, e não seu emissor, para se definir o conteúdo a ser transmitido (REDIG, 2004). No entanto, quanto maior o público a que se destina determinada informação, mais complexa se torna a definição do conteúdo, uma vez que também as singularidades e particularidades provavelmente se tornem presentes de forma proporcional.

Quanto à forma da mensagem, Redig (2004) define sete qualidades do design de informação: (1) analogia em relação ao conteúdo, o 
que, segundo o autor, é determinante para a existência do design de informação; (2) clareza, também considerada imprescindível, mas muitas vezes ausente; (3) concisão, excluindo-se signos ou palavras supérfluas ou dispensáveis; (4) ênfase, para destacar itens mais importantes da mensagem, conferindo legibilidade e identidade a ela; (5) coloquialidade, dependendo do objetivo e do destinatário da mensagem; (6) consistência, fazendo com que cada signo, dentro de seu contexto, corresponda sempre a um mesmo significado; e (7) cordialidade, por uma questão de respeito. Observa-se que as quatro primeiras qualidades citadas por Redig (2004), ou seja, a analogia, a clareza, a concisão e a ênfase, já haviam sido citadas por outros autores neste artigo, o que pode indicar que são, portanto, aspectos considerados de maior importância para o processo de design de informação.

As qualidades relacionadas ao tempo na transmissão da mensagem, para Redig (2004), são: (1) o senso de oportunidade, sendo essencial que a informação apareça quando o receptor precisa dela, não aparecendo quando ele não precisa; e (2) a estabilidade ou continuidade dos códigos utilizados.

No entanto, uma questão importante é levantada por Jacobson (2000), ao destacar a forte relação entre o sucesso do design de informação e o contexto em que ele se apresenta. Devido às dificuldades em se replicar condições como o cenário em que ocorre a transferência de conhecimento, os indivíduos envolvidos, os dispositivos empregados e os objetivos de quem produziu o projeto e de quem o utiliza, é quase impossível, de acordo com o autor, prever cientificamente, para qualquer configuração específica, o que vai funcionar e o que não vai.

\section{Considerações finais}

O mapa das linhas de metrô de Londres, de Harry C. Beck, e o método Isotype, de Otto Neurath, ambos identificados como marcos para a origem do design de informação, foram desenvolvidos na década de 1930, em um momento ainda bastante distante do surgimento das tecnologias digitais. No cenário atual, em que interfaces gráficodigitais se tornam cada vez mais presentes no cotidiano de grande parte da população mundial, os limites entre o design de informação e o design de interfaces ou interações nem sempre são muito claros. Embora o projeto de interfaces para sistemas digitais interativos abranja aspectos que não são contemplados no escopo do design de informação, como comportamento de elementos gráficos, navegação e, mais recentemente, até gestos executados por seus usuários, por outro lado, os princípios e fundamentos do design de informação apresentados neste artigo podem ser considerados de grande valia para profissionais envolvidos no projeto de interfaces digitais. 
Observa-se, dentre as definições de design de informação expostas, que os autores abordados, de modo geral, concordam que essa disciplina ou campo de estudo diz respeito à disponibilização de informações, de forma clara e objetiva, levando-se em consideração as pessoas a quem tais informações se destinam, ou seja, seus usuários, receptores ou destinatários.

Assim, a partir do exposto neste artigo, observa-se a necessidade de se atentar às possíveis estratégias para se reforçar, diferenciar e suportar conteúdos a serem apresentados, seja em suporte físico ou digital. Também se deve considerar, em um projeto de design de informação, aquele que fará uso das informações que se pretende transmitir, de modo que o conteúdo seja disponibilizado adequadamente.

Com o desenvolvimento tecnológico e o consequente aumento da disseminação de informações em diferentes suportes, a visualização de dados se tornou ainda mais complexa e, nesse contexto, o design de informação pode ser considerado um importante recurso para apresentar diferentes conteúdos, de maneira adequada e clara, também em meios digitais.

\section{Referências}

BERTIN, J. (1986). A neográfica e o tratamento gráfico da informação. Curitiba: Editora da Universidade Federal do Paraná.

BONSIEPE, G. (1997a). Design: do material ao digital. Florianópolis: FIESC/IEL. BONSIEPE, G. (1997b). Design - the blind spot of theory or Visuality | Discursivity or Theory - the blind spot of design. Disponível em: <www.guibonsiepe.com/ pdffiles/visudisc.pdf> . Acesso em: 22 Maio 2012.

Bonsiepe, G. (1999). Del objeto a la interfase: mutaciones del diseño. Buenos Aires: Ediciones Infinito.

BonsiePe, G. (2011). Design, cultura e sociedade. São Paulo: Blucher. BURKE, C. (2009). Isotype: representing social facts pictorially. Data Designed for Decisions Conference, OECD, Paris, jun. Disponível em: <http:// isotyperevisited.org/Isotype_representing_social_facts_pictorially.pdf $>$. Acesso em: 14 jun. 2014.

CARdoso, R. (2012). Design para um mundo complexo. São Paulo: Cosac Naify FIELD, K. (2011) Editorial: Celebrating Jacques Bertin. The Cartographic Journal, v. 48, n. 2. International Cartographic Conference, Paris. p. 79-80. Disponível em: <http://www.maneyonline.com/doi/pdfplus/10.1179/0008704 11X13032074303571>. Acesso em: 13 jun. 2014.

FRASCARA, J. (2004). Communication design: principles, methods, and practice. New York: Allworth Press.

FRASCARA. J. (2011). ¿Qué es el diseño de información? Buenos Aires: Ediciones Infinito.

HORN, R. E. (2000). Information design: emergence of a new profession. In: JACOBSON, Robert (ed.). Information design. Cambridge (MA): The MIT Press. 
IIID. (2007). International Institute for Information Design. [s.1.]. Disponível em: < http://www.iiid.net/Information.aspx>. Acesso em: 08 set. 2013.

IIID. (2011). 25th anniversary. [s.l.]. Disponível em: <http://www.iiid.net/ Anniversary.aspx>. Acesso em 23 out. 2013.

IIID. (2013). Information design: core compentencies. What information designers know and can do. Viena: IIID, 2007. Disponível em: <http://www.iiid.net/ PDFs/idxPublication.pdf> Acesso em: 09 set. 2013.

JACobson, R. (ed.). (2000). Information design. Cambridge (MA): The MIT Press. Johnson, s. (2001) Cultura da interface: como o computador transforma nossa maneira de criar e comunicar. Rio de Janeiro: Jorge Zahar.

KRAAK, M.-J. (2011) Book and atlas reviews. The Cartographic Journal, v. 48, n. 2. International Cartographic Conference, Paris. p. 153. Disponível em: < http:// www.maneyonline.com/doi/pdfplus/10.1179/o00870411X13033822531071>. Acesso em: 13 jun. 2014.

LEMos, A. (1997). Anjos interativos e retribalização do mundo. Sobre interatividade e interfaces digitais. Revista Tendências XXI, v.2. Lisboa: APDC, p. 19-29, 1997. Disponível em: <http://www.facom.ufba.br/ciberpesquisa/ lemos/interativo.pdf >. Acesso em: 23 Maio 2012.

MALAMED, C. (2009). Visual language for designers: principles for creating graphics that people understand. Beverly: Rockport Publishers.

MEgGS, P. B., PURVIS, A. W. (1998). Meggs' history of graphic design. Hoboken, NJ: John Wiley \& Sons, .

MIJKSENAAR, P. (1997). Visual function: an introduction to information design. Rotterdam: 010 Publishers, .

MORITA, T. Reflections on the works of Jacques Bertin: from sign theory to cartographic discourse. The Cartographic Journal, v. 48, n. 2. International Cartographic Conference, Paris. p. 86-91, 2011. Disponível em: <http://www. maneyonline.com/doi/pdfplus/10.1179/000870411X13038059668604>. Acesso em: 13 jun. 2014.

REDIG, J. (2012). Não há cidadania sem informação, nem informação sem design. Infodesign, v.1, n.1. [s.1.] p. 58-66, 2004. Disponível em: <http://www. infodesign.org.br/revista/public/journals/1/No.1Vol.12004/InfoDesign_v1_ n1_2004_04_Redig.pdf>. Acesso em: 06 nov.

ROYO, J. (2008) Design digital. São Paulo: Rosari.

SBDi. (2006). Sociedade Brasileira de Design da Informação. [s.l.]. Disponível em: <http://www.sbdi.org.br/>. Acesso: em 25 fev. 2013.

SHEDROFF, N. (2000) Information interaction design: a unified field theory of design. In: JACOBSON, Robert (ed.). Information design. Cambridge (MA): The MIT Press.

Tufte, E. (2006). Beautiful evidence. Cheshire: Graphic Press.

TUFTE, E. (2001). The visual display of quantitative information. Cheshire: Graphic Press.

WALKER, s. (2014). Explaining history to children: Otto and Marie Neurath's work on the visual history of mankind. Journal of Design History, v. 25, n. 4, online, p. 345-362, 2012. Disponível em: <http://jdh-oxfordjournals-org.ez46. periodicos.capes.gov.br/content/25/4/345.full.pdf $>$. Acesso em: 14 jun.

WARE, C. (2008). Visual thinking for design. Burlington (MA): Morgan Kaufmann. 


\section{Sobre os autores}

\section{Fernanda S. Quintão}

$<$ fernandaq@gmail.com>

Mestra em Design e Expressão Gráfica (UFSC). Em sua dissertação, pesquisou sobre o design de informação em plataformas colaborativas online que utilizam imagens cartográficas digitais.

\section{Ricardo Triska.}

<ricardo.triska@gmail.com>

Dr. Eng., UFSC. Pesquisador CNPQ, nivel 2, participa em projetos no DesignLab / UFSC na área de Design da Informação, Animação e Gestão de Projetos. Pesquisa sobre linguagem subliminar e design instrucional. Atual Coordenador da Área de Arquitetura, Urbanismo e Design junto à CAPES.

Artigo recebido em 22 abr. 2014, aprovado em 21 jul. 2014. 